\title{
A classe nos une, o gênero nos divide: imbricações entre patriarcado e capitalismo
}

\author{
Class unites us, gender divides us: imbrications of patriarchy and capitalism
}

\section{Ana Carolina Brandão VAZQUEZ*}

Resumo: O presente artigo visa contribuir para a discussão acerca da opressão/exploração sobre as mulheres a partir do método materialista histórico-dialético cunhado por Karl Marx. No ano em que completa 135 anos de sua morte, a teoria crítica formulada por ele e Engels ainda responde com maestria às questões impostas pelo modo de produção capitalista. No que tange à questão das mulheres, não é diferente. Ao mesmo tempo em que situa a opressão/exploração que incide sobre as mulheres desde bases materiais e objetivas, com significativo aprofundamento a partir da instituição da propriedade privada, o materialismo histórico nos permite entender a forma dialética pela qual patriarcado e capitalismo se implicam, exercendo, ao mesmo tempo, opressões distintas e combinadas, oferecendo a ferramenta necessária para entender que se, em determinada medida, o gênero nos une, a classe nos divide, dando relevo à unidade de classe necessária para superação da sociedade burguesa, por outro lado, a classe nos une, mas o gênero nos divide, trazendo para a cena analítica a opressão patriarcal a qual estão sujeitas as mulheres independente da classe social.

Palavras-chave: Patriarcado. Capitalismo. Luta de classes. Violência contra a mulher. Materialismo históricodialético.

\begin{abstract}
This paper aims to contribute to the discussion around the oppression/exploitation of women using the historical-dialectic materialist method coined by Karl Marx. 135 years after his death, the critical theory formulated by him and Engels still masterfully answers the questions posed by the capitalist mode of production. However, as far as women are concerned, not much has changed. At the same time as it addresses the oppression/exploitation of women from a material and objective standpoint, a situation significantly deepened by the institution of private property, historic materialism allows us to understand the dialectic forms by which patriarchy and capitalism are implicated in exerting both distinct and combined forms of oppression. This methodology provides the tools required to understand that, on the one hand, gender unites us and class divides, thereby emphasising the unity of class necessary to overcame bourgeois society, whilst on the other hand, class unites us and gender divides, thereby allowing us to analyse the patriarchal oppression to which women are subject, regardless of social class.
\end{abstract}

Keywords: Patriarchy. Capitalism. Class struggle. Violence against woman. Historical-dialectic materialism.

Submetido em: 11/4/2018. Revisado em: 6/6/2018. Aceito em: 3/7/2018.

\section{INTRODUÇÃO}

$\mathrm{N}$ corrente ano, comemoramos o bicentenário de nascimento de Karl Marx ao mesmo tempo em que completa 135 anos de sua morte, o que nos leva a refletir sobre seu legado intelectual e sua contribuição para a compreensão da sociedade burguesa. No que tange a este artigo, centraremo-nos na análise da questão da mulher na sociedade de classes, utilizando para tanto o método materialista histórico-dialético.

\footnotetext{
* Assistente Social. Doutoranda em Serviço Social pelo Programa de Pós-Graduação em Serviço Social da Universidade Federal do Rio de Janeiro. (UFRJ, Rio de Janeiro, Brasil). Av. Pasteur, 250, Urca, Rio de Janeiro (RJ), 22290-240. E-mail: <acbvazquez@gmail.com>. ORC ID: <https://orcid.org/oooo-0002-7189$0384>$.
} 
Pensar a questão da mulher à luz do materialismo histórico-dialético, significa entender a opressão das mulheres a partir de uma raiz material, atrelada ao surgimento da propriedade privada. Cabe destacar, entretanto, que se esta opressão e exploração é aprofundada com o surgimento do modo de produção capitalista, é anterior a ele. Nesse sentido, patriarcado e capitalismo se conjugam agudizando a opressão e exploração sobre as mulheres especificamente. Se no capitalismo a exploração recai sobre a classe trabalhadora, alijada dos meios de produção, no caso das mulheres, soma-se a isso a opressão advinda do patriarcado. Logo, pensar opressão e exploração sobre as mulheres sob um ponto de vista materialista dialético implica pensar necessariamente a intersecção dessas opressões ou, como diz Saffi oti, o "nó" que as indissocia.

\section{SOBRE O MÉTODO EM MARX}

Ao refletirmos acerca das contribuições da teoria marxiana ${ }^{1}$ para a compreensão da sociedade burguesa, pensamos ser o método materialista histórico-dialético, inaugurado por Marx, o que permite que suas análises permaneçam tão atuais a despeito das profundas transformações pelas quais o modo de produção capitalista passou desde sua morte, em 1883.

Ancorado nos estudos de Hegel sobre a dialética e o movimento do real, Marx subverte as premissas do método hegeliano e as assenta sobre bases materiais: o trabalho. A dialética hegeliana traz a contradição como força motriz do ser. Para $\mathrm{Hegel}^{2}$, o ser sem contradição é puramente abstrato; o movimento constitui o ser. Nesse sentido, o pensamento hegeliano não é apartado do real, mas antes, parte dele. Partindo do concreto, Hegel observa que o real é mutante e não estático, concebendo, portanto, a unidade entre forma e conteúdo, pensamento e realidade. Dessa forma, traz para o pensamento dialético o princípio da negatividade. A negatividade é a expressão do movimento dialético; é a contradição, o conflito constitutivo do ser. Nessa perspectiva de análise, todo conflito é uma relação de unidade. Hegel propõe, por conseguinte, a tríade dialética: tese - antítese - síntese.

A investigação metodológica, em Hegel, consiste na integração do pensamento por meio da discussão e da controvérsia. A apresentação da tese pressupõe, indubitavelmente, a sua ant ítese, seu contra-argumento, sua negação: desse confronto surge a síntese. Ressaltamos, todavia, que a síntese, apesar de ser a elevação a um nível superior da tese e da antítese, não as elimina totalmente, mas conserva alguns de seus aspectos. A síntese é a consolidação da interpenetração dos contrários naquilo que agregam para elevar-se.

Apesar de conceber a realidade como um processo em movimento, compreendendo as suas contradições, Hegel é um pensador idealista, logo, a resolução dos problemas reais encontra-se no plano ideal, restringindo o movimento dialético à esfera do pensamento. Por conseguinte, Hegel propõe um sistema fechado, uma totalidade acabada. O movimento do real gera as contradições que são apreendidas e resolvidas no plano das ideias. Nessa perspectiva, Hegel elabora o conceito de Espírito (ou Ideia) Absoluto, que seria a força superior que mo-

\footnotetext{
1 Ao longo do texto, quando nos referirmos diretamente às obras e estudos de Marx , usaremos a expressão teoria marxiana. Quando a referência for a autores que se apropriaram das análises feitas por Marx e Engels, usaremos teoria marxista.

2 A referência utilizada para análise da dialética em Hegel foi o estudo de Lênin sobre o pensador alemão, contido em Lênin (2011).
}

Argum., Vitória, v. 10, n. 2, p. 125-137, maio/ago. 2018. 
ve a realidade. Ou seja, apesar da razão ser dialética e objetiva, é a partir do ideal que se constitui o real; a consciência determina a existência. Desse modo, podemos inferir que, para Hegel, o homem é um ser ontogenético, criador de si mesmo. A dita “inversão" marxiana feita à dialética de Hegel reside exatamente neste ponto: para Marx é a existência que determina a consciência. Nesse sentido, a grande contribuição de Marx consiste em pensar a objetivação do homem através do desenvolvimento das forças produtivas, da transformação da natureza através do trabalho e, consequentemente, da realidade concreto-material. Ou, nas palavras de Marx e Engels, não se trata de

[...] explicar a práxis partindo da ideia, mas de explicar as formações ideais a partir da práxis material e chegar, com isso, ao resultado de que todas as formas e [todos os] produtos da consciência não podem ser dissolvidos por obra da crítica espiritual [...]. Essa concepção mostra que a história não termina por dissolver-se, como 'espírito do espírito', na 'autoconsciência', mas que em cada um dos seus estágios encontra-se um resultado material, uma soma de forças de produção, uma relação historicamente estabelecida com a natureza e que os indivíduos estabelecem uns com os outros [...] portanto, as circunstâncias fazem os homens, assim como os homens fazem as circunstâncias (MARX; ENGELS, 2007, p. 43).

A História, portanto, para Marx, é um processo forjado através de avanços e retrocessos; continuidades e rupturas. Desta forma, Marx se coloca um conjunto de tensões que não podem ser resolvidas a partir de uma ótica puramente teórico-política, deslocando o eixo de análise do ideal para o material. A solução não consiste apenas no domínio teórico, mas na ação prática. Assim, na unidade dialética entre teoria/prática, a práxis torna-se elemento fundamental da dialética materialista.

Marx considera a realidade como uma totalidade aberta, em eterno movimento, modificando e sendo modificada pelos processos de criação da práxis humana. Totalidade, no sentido marxiano, não se restringe à soma das partes, mas a um complexo de complexos que se auto-implicam e se explicam mutuamente.

No que tange aos estudos acerca da opressão/exploração das mulheres, o método materialista histórico-dialético nos permite entender a raiz dessa opressão, desvinculando-a do discurso da inferioridade biológica e assentando-a sobre bases materiais forjadas no decorrer do desenvolvimento histórico-social. Nesse sentido, dado que a desigualdade entre homens e mulheres não se dá de forma natural, ao contrário, é construída historicamente, a práxis se torna elemento fundamental no processo de emancipação tanto das mulheres, como do conjunto da classe trabalhadora.

\section{A IMPORTÂNCIA DE SE NOMEAR A OPRESSÃO: PATRIARCADOX GÊNERO3}

Remontando às origens do termo patriarcado, nos deparamos com alterações em seu significado ao longo da História. Em seu primeiro sentido histórico, datado de antes do século XIX, o termo designava "[...] os dignatários da Igreja, segundo os usos dos autores sagrados,

\footnotetext{
3 A polêmica em torno do uso dos conceitos de gênero e patriarcado pelas intelectuais feministas é ampla e foge aos limites deste trabalho. Para um maior aprofundamento no debate recomendamos ver Scott (1989); Pateman (1993); Saffioti (2015); Arruza (2015); Hartmann (1979) e Nye (1995).
}

Argum., Vitória, v. 10, n. 2, p. 135-147, maio/ago. 2018. 
para os quais patriarcas são os primeiros chefes de família que viveram, seja antes, seja depois do Dilúvio" (DELPHY, 2009, p. 175). Ao analisar a origem semântica da palavra, Delphy destaca que patriarcado advém "[...] da combinação das palavras gregas pater (pai) e arkher (origem e comando). Portanto, patriarcado é literalmente a 'autoridade do pai' (DELPHY, 2009, p. 175). A autora salienta, entretanto, que o radical pater não faz referência ao conceito contemporâneo de pai, não estabelecendo, necessariamente, um vínculo biológico. Dessa maneira, patriarcado se refere à autoridade masculina, tenha ela vínculos biológicos ou não.

O segundo sentido atribuído ao patriarcado, de acordo com Delphy, provém dos escritos de Bachofen e Morgan, posteriormente aprofundados por Engels, referent es aos estudos antropológicos sobre a constituição da família no seio de antigas civilizações em que a organização social se dava em torno da linhagem feminina. Esse direito materno teria sido, paulatinamente, substituído por um direito paterno, o qual Bachofen chama de patriarcado em aberta contraposição ao matriarcado que teria existido nessas sociedades. ${ }^{4}$

Na década de 196o, com a segunda onda ${ }^{5}$ do movimento feminista, atribui-se um terceiro sentido ao termo patriarcado, que passa a designar "[...] uma formação social em que os homens detêm o poder" (DELPHY, 2009, p. 174). Algumas intelectuais se destacam na defesa desta ressignificação do termo, atribuindo-lhe um significado que remonta a uma dominação estrutural e coletiva, que ultrapassa os vínculos biológicos e familiares e se espraia para o corpo social, estabelecendo uma relação de poder entre homens e mulheres, em que cabe aos homens o papel da dominação e às mulheres, a sujeição.

Segundo Pateman (1993), data da década de 1970, o ressurgimento das discussões acerca da teoria do contrato social. No rastro dessas discussões, e em contraposição a elas, a autora formula a teoria do contrato sexual sem a qual, segundo ela, não é possível compreender os verdadeiros termos do contrato social e, consequentemente, o surgimento da sociedade civil. A teoria do contrato sustenta que as relações sociais livres foram substituídas por relações contratuais, em que o contrato firma um compromisso que atende igualmente ambas as partes. Pateman chama atenção, entretanto, para o fato de que essa relação contratual não acontece sob bases igualitárias, principalmente no que tange à relação estabelecida entre homens e mulheres. Para ela,

O contrato original é um pacto sexual-social, mas a história do contrato sexual tem sido sufocada. As versões tradicionais da teoria do contrato social não examinam toda a história e os teóricos contemporâneos do contrato não dão nenhuma indicação de que metade do acordo está faltando. A história do contrato sexual também trata da gênese do direito político e explica por que o exercício desse direito é legitimado; porém, essa história trata o direito político como direito sexual ou instância patriarcal - o poder que os homens exercem sobre as mulheres. A metade perdida da história como uma forma caracteristicamente moderna de patriarcado se estabelece. A

\footnotetext{
4 Vale ressaltar que muitas autoras feministas rechaçam a ideia de um matriarcado original, defendendo que as sociedades sempreforam organizadas entorno do exercício da autoridade masculina, o que acontecia em maior ou menor grau, mas que não impedia que as mulheres desempenhassem papéis de prestígio e colaboração no interior do corpo social.

5 A segunda onda do movimento feminista marca a década de 1960 dando ênfase à dominação masculina sobre as mulheres, marcando o caráter político-ideológico desta dominação, rompendo a dicotomia entre público e privado, ficando conhecida pelo slogan "o pessoal é político", texto da autora Carol Hanisch.
}

Argum., Vitória, v. 10, n. 2, p. 125-137, maio/ago. 2018. 
nova ordem social civil criada através do contrato original é uma ordem social patriarcal (PATEMAN, 1993, p. 15-16).

No que se refere ao patriarcado, Pateman salienta que se trata de "[...] uma forma de poder político" (PATEMAN, 1993, p. 38).

Não obstante à reivindicação política do uso de patriarcado pelas feministas de segunda on$\mathrm{da}$, algumas autoras recusam seu uso pautadas na premissa de que o termo se refere a uma conjuntura histórica específica e sua transposição para explicar a dominação masculina sobre as mulheres na contemporaneidade não pode ser feita sem incorrerem anacronismos. Nesse sentido, uma das objeções feitas ao uso de patriarcado como conceito que pretende definir a opressão sofrida pelas mulheres se dá em torno de uma suposta generalidade, transformando-o em algo a-histórico e transgeográfico.

Para Pateman, todavia, patriarcado é o único termo capaz de dar a correta dimensão da opressão exercida sobre as mulheres pelo simples fato de serem mulheres. De acordo com a autora, "[...] se o problema não for nomeado, o patriarcado poderá muito bem ser habilmente jogado na obscuridade, por debaixo das categorias convencionais da análise política" (PATEMAN, 1993, p. 39). E uma dessas categorias certamente foi o gênero.

Podemos inferir que uma das principais intelectuais que reivindica o conceito de gênero como uma categoria útil para análise histórica ${ }^{6}$ é Joan Scott. De acordo com Scott, as intelectuais feministas, em especial as historiadoras, utilizaram uma gama de abordagens teóricas a fim de categorizar e analisar os problemas de gênero, dentre as quais as mais proeminentes são: 1) as teorias feministas sobre o patriarcado; 2) a crítica feminista tendo por base a tradição marxista;3) a explicação do gênero a partir do pós-estruturalismo francês, em especial à teoria psicanalítica ancorada nos estudos de Lacan.

À primeira, Scott (1989) rechaça, ao dizer que as teorias sobre o patriarcado não articulam a desigualdade entre homens e mulheres a outras dimensões da vida social, reduzindo a dominação masculina à apropriação da capacidade reprodutiva das mulheres, baseando toda a sua análise na diferença biológica entre os sexos. Segundo a autora,

[...] uma teoria que se baseia na variável única da diferença física é problemática para os (as) historiadores (as): ela pressupõe um sentido coerente ou inerente ao corpo humano - fora qualquer construção sócio-cultural - e, portanto, a não historicidade de gênero em si. De certo ponto de vista, a história se torna um epifenômeno que oferece variações intermináveis sobre o tema imutável de uma desigualdade de gênero fixa (SCOTT, 1989, p. 10).

Às feministas marxistas, Scott critica o que ela chama de "[...] exigência de encontrar uma explicação 'material' para o gênero" (SCOTT, 1989, p. 10). Para a autora, as feministas marxistas sobrepõem as questões econômicas às de gênero e, na ânsia de "encaixar" as análises sobre a questão da mulher no escopo geral da luta de classes, não permitiram o desenvolvimento de novas perspectivas de análise. Nas palavras de Scott, “[...] no interior do marxismo,

${ }^{6}$ Alusão ao célebre artigo da historiadora inglesa, Gênero: uma categoria útil para análise histórica, 1989.

Argum., Vitória, v. 10, n. 2, p. 135-147, maio/ago. 2018. 
o conceito de gênero foi por muito tempo tratado como subproduto de estruturas econômicas mutantes: o gênero não tem tido o seu próprio estatuto de análise” (SCOTT, 1989, p. 13).

No que tange às teorias pós-estruturalistas francesas, Scott salienta que centram seu interesse "[...] nas primeiras etapas do desenvolvimento da criança com o objetivo de encontrar indicações sobre a formação da identidade de gênero" (1989, p. 14). Em sua crítica, Scott destaca que essa teoria

[...] faz depender a produção da identidade de gênero e a gênese da mudança, de estruturas de interrelação relativamente pequenas [...] Essa interpretação limita o conceito de gênero à esfera da família e à experiência doméstica, e para o (a) historiador(a) ela não deixa meios de ligar esse conceito (nem o indivíduo) com outros sistemas sociais, econômicos, políticos ou de poder (SCOTT, 1989, p. 15).

Por fim, Scott define gênero como sendo "[...] um elemento constitutivo das relações sociais baseado nas diferenças percebidas entre os sexos e como uma forma primeira de significar as relações de poder" (1989, p. 21). Com isso a autora chama a atenção para o gênero como um conflito baseado principalmente nas relações de poder.

O gênero é uma das referências recorrentes pelas quais o poder político foi concebido, legitimado e criticado. Ele se refere à oposição masculino/feminino e fundamenta ao mesmo tempo seu sentido. Para reivindicar o poder político, a referência tem que parecer segura e fixa fora de qualquer construção humana, fazendo parte da ordem natural ou divina. Desta forma, a oposição binária e o processo social das relações de gênero tornam-se, os dois, parte do sentido de poder, ele mesmo. Colocar em questão ou mudar um aspecto ameaça o sistema por inteiro (SCOTT, 1989, p. 27).

Contudo, a despeito das críticas direcionadas às outras teorias que pensam a opressão da mulher sob diferentes perspectivas, apesar de apontar claramente qual sua visão sobre gênero, a autora não soluciona, a partir dessa categoria, o problema teórico que se coloca:a raiz da opressão da mulher.

De acordo com Saffioti (2015), gênero não se reduz a uma categoria de análise, embora possa funcionar como tal. Em interlocução com o artigo de Joan Scott supracitado, Saffioti salienta que "[...] gênero não implica necessariamente desigualdade ou poder, nem aponta a parte oprimida" (SAFFIOTI, 2015, p. 110). Nesse sentido, Saffioti enfatiza a neutralidade embutida no conceito de gênero, transformando-o em uma noção muito mais ampla e aberta no que tange à marcação dos sujeitos do binômio dominação-exploração. Não obstante, para a autora, gênero e patriarcado não se excluem, mas se complementam de modo que

O exposto permite verificar que o gênero é aqui entendido como muito mais vasto que o patriarcado, na medida em que neste as relações são hierarquizadas entre seres socialmente desiguais, enquanto o gênero compreende também relações igualitárias. Desta forma, o patriarcado é um caso específico das relações de gênero (SAFFIOTI, 2015, p. 126).

Lia Zanotta Machado (200o) também problematiza a oposição entre gênero e patriarcado, salientando que se tratam de conceitos distintos incidindo sobre dimensões distintas - mas complementares - da vida social. Deste modo, patriarcado remete a uma certa rigidez que exige, necessariamente, uma dominação masculina e subordinação feminina, não havendo

Argum., Vitória, v. 10, n. 2, p. 125-137, maio/ago. 2018. 
espaço para subversões. Gênero, ao contrário, está ligado à ideia de que as relações são construídas e transformáveis, permitindo certa fluidez e mobilidade.

A fim de ilustrar a maior instrumentalidade do conceito de gênero no que se refere a compreender as relações entre os sexos na contemporaneidade, Machado apresenta resultados parciais de uma pesquisa sobre violência contra a mulher com ênfase na "[...] conflitualidade e a violência nas relações amorosas e familiares” (MACHADO, 200o, p. 13). Para tanto, trabalha com a simultaneidade do que chama de códigos relacionais da honra e códigos baseados nos valores do individualismo de direitos, em que o primeiro responde à atuação dos sujeitos frente a um conjunto de regras de moralidade, e o segundo diz respeito às "[...] ideias de igualdade, liberdade e cidadania” (MACHADO, 200o, p. 14). Estes dois conceitos se imbricam a partir - e especialmente - do contrato conjugal, em que são atribuídos papéis de gênero a serem desempenhados por homens e mulheres, onde ao homem cabe o papel do provedor, e à mulher da castidade e domesticidade.

Sob esta perspectiva, em nome da honra e do exercício do seu papel de provedor, os homens “[...] podem controlar, fiscalizar e punir suas companheiras" (MACHADO, 200o, p. 14). A violência física, ainda que reconhecidamente ilegítima, ganha legitimidade no momento que é exercida para garantir a honra masculina, supostamente aviltada. Do outro lado do contrato conjugal, estão as mulheres que, segundo Machado, ainda que aceitem a ideia de deveres distintos, não legitimam o exercício do poder desigual entre os sexos. Nesse sentido, salienta:

[...] a minha percepção é a de que as concepções de gênero e as expectativas sobre as relações de gênero, na dimensão dos relacionamentos conjugais e amorosos, estão em franca ebulição. Os contratos conjugais tradicionais, embora vigentes, não são mais capazes de conformar expectativas consensuais e semelhantes entre os pontos de vista femininos e masculinos. As concepções femininas já introduziram no âmago do 'contrato social privado' a ideia de que este contrato só pode se dar entre indivíduos livres e iguais, produzindo a inaceitabilidade do reconhecimento dos direitos diferenc $i$ ais (isto é, 'naturais) dos homens (MACHADO, 2000, p 15, grifos nossos).

O problema que se coloca nesta perspectiva de análise é o risco de se relegar a violência contra a mulher ao âmbito individual. Ainda que as mulheres percebam e resolvam romper com o ciclo da violência doméstica, não estão livres de sofrê-la. Isto porque a dominação masculina tem caráter estruturante das relações entre os sexos, dando a o homem - muitas vezes em nome da honra - o poder de subjugação da mulher.

O patriarcado é um sistema estrutural que não se remete apenas à esfera privada e conjugal. Diz respeito à dominação masculina como forma de relação social de todo homem com toda mulher. Nesse sentido, o conceito de patriarcado é o mais adequado para explicar as diferentes formas de opressão vivenciadas pelas mulheres.

A longa explanação acerca dos conceitos de patriarcado e gênero se faz necessária no sentido de marcar tanto o sujeito que sofre a opressão, quanto aquele que a pratica. Não obstante o conceito de gênero demarcar construções sociais referentes ao masculino e feminino, em que tudo que se aproxima do signo feminino tem status de subalterno e, portanto, passível de violência, oferece uma generalidade no que tange à análise das relações de violência, não 
sendo um marcador preciso da violência contra as mulheres em função de seu sexo. No nosso entender, mascara, portanto, a violência misógina que atinge de forma singular os corpos femininos. Nesse sentido, mais do que um uso histórico, utilizamos o termo patriarcado como marcador de uma posição política, que nomeia os sujeitos da violência: os homens assumem a posição de opressores e as mulheres de oprimidas.

\section{MARXISMO E FEMINISMO: O GÊNERO NOS UNE, A CLASSE NOS DIVIDE?7}

O método materialista histórico-dialético se faz necessário para analisarmos a questão da opressão/exploração das mulheres exatamente por permitir entendê-la em sua totalidade, implicada que está em diversos processos que, longe de se excluírem, imbricam-se formando o que Saffioti chama de "nó". Na esteira da tradição marxista, a autora enfatiza a importância de se analisar a opressão/exploração da mulher sob uma perspectiva de totalidade que só pode ser alcançada se pensarmos as diferentes opressões a que estão expostas as mulheres, levando em consideração, além da questão de gênero, as de classe e raça/etnia. Nesse sentido, Saffioti ratifica que,

[...] quando se consideram os embriões de classe, pode-se retroceder às sociedades escravocratas antigas. Mesmo neste caso, as classes sociais têm uma história muito mais curta que o gênero. Desta forma, as classes sociais são, desde de sua gênese, um fenômeno gendrado. Por sua vez, uma série de transformações no gênero são introduzidas pela emergência das classes. Para amarrar melhor esta questão, precisa-se juntar o racismo. O nó formado por essas três contradições apresenta uma qualidade distinta das determinações que o integram. Não se trata de somar racismo + gênero + classe social, mas de perceber a realidade compósita e nova que resulta desta fusão (SAFFIOTI, 2015, p. 122).

Sabemos que o movimento feminista que surge com mais potência ao longo do século XIX e início do século XX, capitaneado pelas sufragistas, foi um movimento de mulheres pertencentes a classes mais privilegiadas, pouco preocupadas com a exploração sofrida pelas mulheres da classe trabalhadora. Pensavam, assim, um feminismo a partir de sua imagem e semelhança, estabelecendo uma mulher universal, que, obviamente, não atendia às reivindicações das mulheres proletárias. A crítica a esse feminismo burguês foi feita pelas feministas socialistas, como Clara Zetkin e Alexandra Kollontai, que denunciavam esse horizonte pela busca da igualdade sem questionar seus próprios privilégios, mantidos dentro da ordem social estabelecida. Nesse sentido, foram as feministas socialistas aquelas que introduziram a importância de se pensar a classe dentro do movimento feminista.

Luís Felipe Miguel (2017) salienta, entretanto, que apesar de introduzir a centralidade da classe no debate feminista, as feministas socialistas e anarquistas não pensaram os rebatimentos distintos que a exploração de classe tem sobre homens e mulheres. Ao analisar as contribuições do feminismo dito de "segunda onda", na década de 196o, Miguel diz que

A parcela do feminismo da 'segunda onda' de que trato aqui acompanhou as pensadoras comunistas e anarquistas em sua recusa a universalizar o ponto de vista das mulheres burguesas. Mas, ao mesmo tempo, buscava enfatizar a relevância específica da desigualdade entre os sexos para explicar a dinâmica social. Tratava-se de entender como o pertencimento de classe gera especificidades nas vivências das mulheres

\footnotetext{
7 Referência à obra de Cecília Toledo (2008).
}

Argum., Vitória, v. 10, n. 2, p. 125-137, maio/ago. 2018. 
e, ao mesmo tempo, como a divisão de gênero atravessava as classes sociais (MIGUEL, 2017, p. 1226).

Desta forma é necessário analisar a complementariedade que se estabelece entre patriarcado e capitalismo. Se as mulheres não são um todo homogêneo (e não são), tampouco o é a cla sse social. E é nesse sentido que o método materialista histórico-dialético demonstra sua atualidade no que concerne ao estudo da opressão/exploração das mulheres, especialmente a partir da consolidação do modo de produção capitalista.

Qual a relevância de, na contemporaneidade, pensar a questão da opressão/exploração da mulher sob as lentes do materialismo histórico-dialético? O que importa para fins da análise da questão da mulher sob uma perspectiva marxista é entendê-la a partir das diferentes opressões/explorações que a constituem. Enquanto mulheres, estamos sujeitas à violência patriarcal que submete nossas vidas e nossos corpos. Aliada ao capitalismo, somos transformadas em objetos de consumo, mercantilizadas; adentramos o processo de produção e reprodução da vida social de maneira precarizada. O capitalismo marca a diferença de classe na opressão patriarcal. Essa diferença diz respeito, inclusive, às formas de combate possíveis dentro da violência patriarcal impetrada. Se hoje vivenciamos uma crescente visibilidade da luta feminista e dos mecanismos de combate à violência contra mulher, o acesso a eles ainda depende muito da condição de raça e classe que nos encontramos. Uma mulher branca pertencente à classe dominante tem muito mais possibilidades de acessar mecanismos de proteção à violência doméstica, por exemplo, do que uma mulher da classe trabalhadora. Se além de trabalhadora, esta mulher for negra, as possibilidades de acesso reduzem ainda mais.

De acordo com o Mapa da Violência 2015 - homicídio de mulheres no Brasil, ${ }^{8}$ há uma discrepância entre o assassinato de mulheres brancas e negras no período de 2003 a 2013: enqua nto o primeiro grupo encontra-se em declínio, o segundo apresenta uma curva ascendente. Os dados do Mapa apontam que o homicídio de mulheres brancas caiu de 1.747 vítimas em 2003, para 1.576 em 2013, representando uma queda de 9,8\% no total de homicídios no período. O homicídio de mulheres negras, todavia, subiu de 1.864 em 2003, para 2.875 em 2013, o que representa um aumento de $54,2 \%$.

Se esses dados já são alarmantes o suficiente se lidos separadamente, ao analisarmos em termos relacionais, a diferença no número de vítimas por homicídio entre os grupos revela a perversidade do sistema patriarcal-racista-capitalista. Segundo o Mapa,

As taxas de homicídio de mulheres brancas caíram 11,9\%: de 3,6 por 100 mil brancas, em 2003, para 3,2 em 2013. Em contrapartida, as taxas das mulheres negras cresceram $19,5 \%$, passando, nesse mesmo período, de 4,5 para 5,4 por 100 mil. Com esse diferencial de crescimento, as taxas de ambos os grupos de mulheres foram se afastando. Essa distância relativa, entre as taxas de vítimas brancas e negras, é o que denominamos índice de vitimização negra, que nada mais é do que a diferença percentual entre as taxas de homicídio de mulheres de ambos os grupos. Vemos que o índice de vitimização negra, em 2003, era de 22,9\%, isso é, proporcionalmente, morriam assas-

\footnotetext{
${ }^{8}$ Agradecemos a historiadora Ana Taisa da Silva Falcão por nos apresentar os dados do Mapa da Violência e por compartilhar conosco suas análises acerca da violência contra mulher. Sem essas discussões muito deste artigo não poderia ser escrito.
}

Argum., Vitória, v. 10, n. 2, p. 135-147, maio/ago. 2018. 
sinadas $22,9 \%$ mais negras do que brancas. O índice foi crescendo lentamente, ao longo dos anos, para, em 2013, chegar a 66,7\% (WAISELFISZ, 2015, p. 31-32).

Quando se debruça sobre a análise dos locais dos crimes, o Mapa revela que, em oposição aos homicídios contra homens - os quais mais da metade ocorrem em locais públicos -, os homicídios contra mulheres chamam atenção pelo percentual expressivo daqueles que acontecem no âmbito do domicílio da vítima. No que tange ao agressor, o Mapa ressalta que, entre as mulheres jovens e adultas (18 a 59 anos), metade dos autores dos crimes eram companheiros ou ex-companheiros das vítimas. Tais dados nos permitem pensar sobre o peso que a violência patriarcal assume, inclusive, nas relações afetivas intraclasses.

Apesar do Mapa não mencionar a classe social das vítimas, tendo em vista a nossa formação social e o peso do regime escravocrata na formação da classe trabalhadora brasileira, podemos depreender que a probabilidade de boa parte das mulheres negras pertencerem a esse estrato de classe é grande. Se pensarmos que, em sua maioria, os relacionamentos afetivos se dão dentro do seio da mesma classe social, não seria leviano afirmar que os agressores também engrossam as fileiras da classe trabalhadora. Cabe, portanto, reafirmarmos que, se a classe nos une, o gênero nos divide. Não estamos com isso hierarquizando opressões e vi olências, nem dizendo que há uma cisão intransponível entre homens e mulheres da classe trabalhadora. Ao contrário, o que intentamos demonstrar é que, se por um lado a luta pela abolição da sociedade de classes deve se dar na unidade da classe trabalhadora, isso não impede que reconheçamos e lutemos contra as outras formas de opressão que se dão no interior da própria classe. Afirmar que patriarcado e capitalismo são sistemas distintos, mas complementares, é fundamental para entendermos qual a raiz e a funcionalidade da opressão/exploração das mulheres na sociedade burguesa. Sob esta perspectiva, no limite, o capitalismo aprofunda a violência patriarcal uma vez que marca a forma diversa como as mulheres a experimentam de acordo com a classe.

\section{CONSIDERAÇÕES FINAIS}

O feminismo ${ }^{9}$, assim como outras lutas identitárias, é também apropriado pelo capitalismo e transformado em mercadoria. Ao mesmo tempo em que vemos mulheres (re)tomando a consciência sobre seus corpos e a opressão/exploração a que são submetidas, presenciamos uma crescente mercantilização das pautas feministas. Todavia, isso transforma todo feminismo em feminismo liberal? Não é possível analisar a opressão da mulher à luz do materialismo histórico-dialético? As lutas identitárias não podem se dar no âmbito da luta pela emancipação humana? Especificar as opressões que determinados grupos sociais sofrem é fragmentar a luta de classes?

Caímos aqui em um impasse dentro mesmo da tradição marxista: de um lado, aqueles que defendem que a unidade na luta proletária só pode se dar entendendo a opressão de classe como primordial, dentro da qual se diluem todas as outras opressões; de outro, os que acreditam que não podemos entender a realidade sem pensarmos as diversas opressões que nos atingem, articulando-as.

9 Utilizamos aqui o termo feminismo de forma ampla e genérica, haja vista que não existe apenas um feminismo, mas sim várias correntes sobre o feminismo.

Argum., Vitória, v. 10, n. 2, p. 125-137, maio/ago. 2018. 
O grande legado da teoria marxiana diz respeito ao método. Uma das grandes armadilhas em que tropeçam teóricos e teóricas marxistas é a forma engessada de utilização deste método. Não nos esqueçamos que ele é um método materialista histórico-dialético. Ou seja, entende a história como processo de continuidades e rupturas, de imbricações, de movimento dinâmico. Nesse sentido, a tentativa de sobrepor e hierarquizar opressões pode levar a assertivas equivocadas, principalmente no que tange à questão da mulher. Não se trata de priorizar ou, no limite, de sobrepor opressões, mas de entendê-las como um nó indissociável. Mulheres são oprimidas por serem mulheres. Mulheres da classe trabalhadora, além da opressão patriarcal, sofrem a exploração de classe. Mulheres negras e trabalhadoras, somam à opressão/exploração de gênero e classe, a opressão advinda do racismo. No limite, existem violências que perpassam a todas nós, mas que se aprofundam de acordo com as clivagens de classe e raça/etnia.

Sob este registro, a despeito da exploração de classe que atinge o conjunto do proletariado, incide sobre a mulher, além desta, a opressão patriarcal que pode sim ser perpetuada no seio de sua própria classe. Tendo em vista que o patriarcado funciona como um sistema de poder no qual se assenta o capitalismo - sistema esse que parte da premissa da dominação masculina sobre as mulheres -, os homens da classe trabalhadora podem exercer (e exercem!) a violência patriarcal sobre suas companheiras.

Portanto, não seria leviano afirmarmos que se a classe nos une, o gênero nos divide. Essa afirmação, contudo, não anula a anterior, tese central dos estudos de Cecília Toledo (20o8), o gênero nos une, a classe nos divide. Ao contrário, partindo do método materialista histórico-dialético, entendemos essas duas dimensões, ao mesmo tempo contrárias e complementares, formando assim uma unidade.

Nas palavras de Kollontai (1907, não paginado), “[...] as mulheres só podem se tornar verdadeiramente livres e iguais em um mundo organizado por novas linhas sociais". Segundo a revolucionária russa, entretanto, isso não significa rejeitar os avanços colocados na questão da mulher no âmbito da sociedade burguesa, uma vez que "[...] todo direito que as mulheres ganham traz-lhe mais perto do objetivo conjunto de emancipação total” (KOLLONTAI, 1907, não paginado). Sob esta perspectiva, podemos inferir que, se não há unidade na luta feminista (e não há, tendo em vista as clivagens de classe e raça/etnia que nos separam), no limite, essa unidade consegue ser alcançada em determinados pontos e somente a curto prazo. As conquistas no âmbito do movimento feminista liberal têm como fim a equiparação dos direitos das mulheres com os homens, inclusive no seu privilégio de opressão e exploração. Nesse sentido, o método materialista dialético nos permite entender as aproximações e afastamentos das mulheres burguesas e trabalhadoras na luta feminista. Perceber a opressão/exploração sobre a mulher como parte de uma totalidade social, imbricada no processo de produção e reprodução das relações sociais, nos permite ir além da aparência fenomênica da violência contra a mulher, seja ela material ou simbólica. Se o patriarcado fundou as raízes da opressão sobre as mulheres, o capitalismo se apropriou desta opressão a fim de aprofundar seu processo de exploração. Podemos inferir, assim, que as mulheres experimentam essa opressão/exploração de maneira distinta. No limite, as mulheres burguesas experimentam a opressão patriarcal, tendo sua luta voltada para o fim da dominação masculina, para equiparação dos direitos entre mulheres e homens (inclusive o direito de exploração de mulheres da classe trabalhadora). Sobre as mulheres trabalhadoras recai, além da opressão pa-

Argum., Vitória, v. 10, n. 2, p. 135-147, maio/ago. 2018. 
triarcal, a exploração de classe, a precarização da vida. Sendo assim, é possível uma unidade na luta feminista?

Sabemos que a burguesia é revolucionária até a tomada de poder, transformando suas pautas particulares em lutas universais. No caso do feminismo burguês não é diferente. O que não significa, entretanto, que não seja necessário. Retomando o pensamento de Kollontai (1907), quando nos diz que qualquer avanço no direito das mulheres, mesmo na sociedade capitalista, soma à luta pela emancipação humana, nosso horizonte revolucionário, entendemos a luta do feminismo liberal pelas garantias individuais como importante também para as mulheres trabalhadoras, uma vez que, como já dissemos, estas também sofrem com a opressão patriarcal. O problema que se coloca é que estas garantias individuais não são suficientes para a libertação das mulheres. Tendo em vista que a dominação masculina não é exercida apenas pelos homens burgueses, a unidade na luta feminista se faz necessária neste sentido, mas deve ir além dele.

\section{REFERÊNCIAS}

ARRUZA, Cinzia. Considerações sobre o gênero: reabrindo o debate sobre patriarcado e/ou capitalismo. Outubro, n. 23, p. 33-58, $1^{\circ}$ semestre 2015. Disponível em:

<http://outubrorevista.com.br/wp-content/uploads/2015/o6/2015_1_04_Cinzia-Arruza.pdf>. Acesso em: 5 abr. 2018.

DELPHY, C. Patriarcado. In: HIRATA, H. et al. (Orgs.). Dicionário crítico do feminismo. São Paulo: Unesp, 2009.

HARTMANN, Heidi. The Unhappy Marriage of Marxism and Feminism: Towards a more Progressive Union. In: NICOLSON, Linda (Ed.). The second wave: a reader in feminist theory. New York: Routledge, 1997 [1979].

KOLLONTAI, Alexandra. Os fundamentos sociais da questão feminina [extratos]. [S.1.]: Marxists, 1907. Disponível em: <https://www.marxists.org/espanol/kollontai/1907/oo1.htm>. Acesso em: 5 abr. 2018.

LÊNIN, V. I. Cadernos sobre a Dialética de Hegel. Rio de Janeiro: UFRJ, 2011.

MACHADO, Lia Zanotta. Perspectivas em confronto: relações de gênero ou patriarcado contemporâneo? Série Antropológica, Brasília (DF), n. 284, 2000.

MARX, Karl; ENGELS, Friedrich. A ideologia alemã. São Paulo: Boitempo, 2007.

MIGUEL, Luis Felipe. Voltando à discussão sobre capitalismo e patriarcado. Estudos Feministas, Florianópolis, v. 25, n. 3, p. 1219-1237, set./dez. 2017.

NYE, Andrea. Teoria feminista e as filosofias do homem. Rio de Janeiro: Rosa dos Tempos, 1995 .

PATEMAN, Carole. O contrato sexual. Rio de Janeiro: Paz e Terra, 1993.

Argum., Vitória, v. 10, n. 2, p. 125-137, maio/ago. 2018. 
SAFFIOTI, Heleieth. Gênero, patriarcado, violência. 2. ed. São Paulo: Expressão Popular; Fundação Perseu Abramo, 2015.

SCOTT, Joan. Gênero: uma categoria útil para análise histórica. New York: Columbia University Press, 1989.

TOLEDO, Cecília. Mulheres: o gênero nos une, a classe nos divide. São Paulo: Sundermann, 2008.

WAISELFISZ, Julio Jacobo. Mapa da Violência 2015: homicídio de mulheres no Brasil. Brasília (DF): Flacso, 2015. 